\title{
Association between pregnancy intention and late initiation of antenatal care among pregnant women in Ethiopia: a systematic review and meta-analysis
}

\author{
Tadesse Tolossa ${ }^{1 *}$ (D) Ebisa Turi ${ }^{1}$, Getahun Fetensa ${ }^{2}$, Ginenus Fekadu ${ }^{3}$ and Fassikaw Kebede ${ }^{4}$
}

\begin{abstract}
Background: Antenatal care is one of the continua of reproductive health care, and inadequate antenatal care utilization results in an adverse feto-maternal outcome. Pregnancy intention is an essential factor that plays a paramount role on timing of antenatal care service. The finding of a few studies conducted on the association between pregnancy intention and late initiation of ANC among pregnant women in Ethiopia presented inconclusive. Therefore, the objective of this systematic review and meta-analysis was to determine the pooled estimate of the association between pregnancy intention and late initiation of ANC among pregnant women in Ethiopia.

Methods: Both published and unpublished studies were accessed through electronic search from databases such as MEDLINE, Scopes, PubMed, CINAHL, PopLine, MedNar, Cochrane library, the JBI Library, the Web of Science, and Google Scholar. All observational studies that were conducted on the association between pregnancy intention and late initiation of ANC among pregnant women in Ethiopia were included. STATA 14.1 version was used for data analysis. A random effects model was used to estimate the pooled estimate with a 95\% confidence interval (CI). The Cochrane $Q$ test statistic and $P$ tests were used to assess heterogeneity. Presence of publication bias was checked by funnel plots and Egger's statistical tests.
\end{abstract}

Results: A total of 670 published and unpublished studies were identified from several databases and fourteen studies fulfilled inclusion criteria and included in the meta-analysis. The overall pooled estimate indicates the odds of late initiation of antenatal care were 2.16 times higher among pregnant women who had unintended pregnancy as compared to pregnant women who had intended pregnancy (OR 2.16, 95\% Cl 1.62, 2.88).

Conclusion: The systematic review and meta-analysis found a statistically significant effect of pregnancy intention on late initiation of antenatal care among pregnant women in Ethiopia. Increased effort should be made to improve women's behavior towards contraceptive use through health education and counseling, especially those with unintended pregnancies. Furthermore, health education, counseling, and communication campaigns related to the timing of ANC and frequency should be promoted nationally.

Keywords: Pregnancy intention, Delayed ANC, Systematic review, Ethiopia

\footnotetext{
*Correspondence: yadanotolasa@gmail.com

'Department of Public Health, Institutes of Health Sciences, Wollega University, Nekemte, Ethiopia

Full list of author information is available at the end of the article
}

C C The Author(s). 2020 Open Access This article is licensed under a Creative Commons Attribution 4.0 International License, which permits use, sharing, adaptation, distribution and reproduction in any medium or format, as long as you give appropriate credit to the original author(s) and the source, provide a link to the Creative Commons licence, and indicate if changes were made. The images or other third party material in this article are included in the article's Creative Commons licence, unless indicated otherwise in a credit line to the material. If material is not included in the article's Creative Commons licence and your intended use is not permitted by statutory regulation or exceeds the permitted use, you will need to obtain permission directly from the copyright holder. To view a copy of this licence, visit http://creativecommons.org/licenses/by/4.0/ The Creative Commons Public Domain Dedication waiver (http://creativecommons.org/publicdomain/zero/1.0/) applies to the data made available in this article, unless otherwise stated in a credit line to the data. 


\section{Background}

Sub-Saharan African (SSA) countries contribute to the highest maternal, newborn, and child mortality, globally. Although maternal health service utilization is associated with a decrement of millions of maternal, newborn, and child death [1], globally, only two-thirds of women received four antenatal care (ANC) visits [2], 80\% of live birth attended by skilled birth attendant [3], and few of them used postnatal care [4]. Maternal mortality is one of the targets of SDGs, in which the target 3.1 calls for the global maternal mortality ratio reduction below 70 deaths per 100,000 live births [5]. Strengthening maternal health service utilization is necessary to accelerate the progress of developing countries and the international community to prevent maternal and child morbidity and reach the related Sustainable Development Goals (SDG) [6].

Antenatal care is one of the continua of reproductive health care which is renowned as a vital maternal service in improving a wide range of health outcomes for women and children [7]. Timely initiation of first antenatal care visit will play an essential role for opening a doorway for maternal and child health continuum of care [1]. It can also ensure optimal health outcomes for women and children, and it is recommended that all pregnant women initiate antenatal care in the first trimester of pregnancy (early antenatal care visit of less than the first 12 weeks $[7,8]$. Inadequate antenatal care utilization such as either late initiation of antenatal care or low frequency of visits results in adverse fetomaternal outcomes [9]. Utilization of at least one antenatal care visit by a skilled provider during pregnancy reduces the risk of neonatal mortality by $39 \%$ in SSA countries [10]. Accordingly, in order to decrease maternal and neonatal mortality, all pregnant women should initiate antenatal care visit during pregnancy as early as possible $[6,7,10]$.

Studies showed that the majority of pregnant women begin their first ANC visit lately. A study conducted in Western Ethiopia indicated that $81.5 \%$ of women got ANC service lately [11]. Another study in Northern Ethiopia also reported that more than half of pregnant women initiated ANC after the recommended period time [12]. A systematic review and meta-analysis conducted on delayed initiation of antenatal care in Ethiopia revealed that the magnitude of delayed ANC was 64\% [13].

Pregnancy intention is also another essential factor that plays a vital role on maternal health service utilization, including the late commencement of antenatal care service. Women experiencing unplanned pregnancies are more likely to delay antenatal care [14, 15]. Unplanned pregnancy is becoming a public health concern both in developed and developing countries [16, 17]. Globally, there were about 99.1 million unintended pregnancies per year in 2010-2014 in the world, and in sub-Saharan Africa, about 65 per 1000 women aged 1544 years bear unintended pregnancy [18].

Unintended pregnancy (mistimed/unwanted in particular) is associated with adverse feto-maternal outcomes. For instance, existing evidence shows the presence of a relationship between unintended childbearing and various misbehaviors such as smoking and alcohol consumption [19]. Moreover, unintended pregnancy is associated with several adverse health outcomes such as poor women's psychological well-being [20], maternal depression and anxiety [21], and inadequate utilization of prenatal care or skilled birth attendance [19, 22, 23]. Overall, it has been established that women who experience an unintended pregnancy are less likely than women with intended pregnancies to seek care [13-15]. Indeed, unintended/mistimed pregnancy is associated with unhealthy perinatal behaviors [19].

Even though there is a high rate of unintended pregnancies in both developed and developing countries and its potential child and maternal adverse health impact, there is a necessity to know more about the associations between pregnancy intention and late initiation of antenatal care visit. To the extent of our knowledge, there has been no systematic review and meta-analysis of pregnancy intention and its association with the late initiation of antenatal care visit. The current meta-analysis focuses on the pooled association between pregnancy intention and late initiation of antenatal care.

\section{Methods}

\section{Search strategy}

The Preferred Reporting Items for Systematic Reviews and Meta-Analyses (PRISMA) checklist was used to report the review [24]. Literature was downloaded to Endnote (version X7.2) to maintain and manage citations and facilitate the review process [25].

At the beginning, we checked for the presence of the existing systematic review and meta-analysis on a similar topic using the trial registries and the Cochrane library to avoid duplication. A systematic search of electronic databases such as MEDLINE, Scopes, PubMed, CINA HL, PopLine, MedNar, Cochrane library, the JBI Library, the Web of Science, and Google Scholar was done. All studies were searched using the key terms "antenatal care, late initiation, delayed initiation, early booking of ANC, pregnancy intention, unintended pregnancy, determinant factors, Ethiopia." Addis Ababa University Digital Library and African digital library were searched to find unpublished papers [26-29]. The search was conducted from September 15, 2019, to October 30, 2019, among studies conducted until October 30, 2019. All authors participated in the search of the literature. 
The pre-defined search terms were used to allow us a comprehensive search of important studies included in our review. All fields within records and Medical Subject Headings ( $\mathrm{MeSH}$ terms) were used to help enlarge the search in advanced PubMed search. The following search strategies were adapted for the various databases using the two important Boolean operators and search engines with initial search terms "delayed initiation" OR "late initiation" OR "early initiation" AND "associated factors" OR "determinant factors" OR "predictors" AND "Antenatal care" [MeSH Terms] AND "pregnant women."

\section{Selection and eligibility criteria Inclusion criteria}

This systematic review and meta-analysis included studies that were conducted on the association between pregnancy intention and late initiation of ANC among pregnant women in Ethiopia. We restricted our searches to human studies published in the English language. Participants were pregnant women and the review considered studies conducted with all observational study design; studies report pregnancy intention as a variable, which were written in English; and all studies are conducted in Ethiopia. All studies that were published in the form of journal articles and master's thesis and dissertations till October 30, 2019, were included. The systematic review and meta-analysis used the PICO (Population, Intervention, Comparison, and Outcomes) framework to assess the eligibility of the articles included. The study population (P) were all pregnant women in Ethiopia, the Intervention (I) was having unintended pregnancy on their last pregnancy, the Comparison (C) was pregnant women who had intended pregnancy on their last pregnancy, and the Outcomes (O) of the interest was pregnant women who booked ANC after 12 weeks of gestational age in some studies or 16 weeks of gestation in other studies.

\section{Exclusion criteria}

We exclude articles that were not accessible after contacting the principal investigator two times by email. We excluded studies found only as abstract since it was difficult to access all essential information required for the analysis.

\section{Outcome measurement}

The primary outcome variable was the association between pregnancy intention and late initiation of ANC. Pregnancy intention was measured by asking a woman's desire about her pregnancy at the time she was pregnant (intended/unintended pregnancy). Accordingly, intention to become pregnant was categorized as intended and unintended pregnancy. Intended pregnancy is when the mother indicated that she wanted to become pregnant on their last pregnancy. Unintended pregnancy is classified into mistimed and unwanted. Both show a pregnancy that had not been wanted at the time conception occurred. Mistimed pregnancies are those pregnancies that were wanted by the woman at some time, but which occurred sooner than they were wanted, and unwanted pregnancies are all pregnancies that occurred when the woman did not want to have any more pregnancies at all $[30,31]$. For this review, delay or late initiation of the first $\mathrm{ANC}$ visit is an initiation of the first $\mathrm{ANC}$ visit in public health facilities by skilled health personnel after 12 weeks of gestation in some studies and after 16 weeks of gestation in others (Table 1).

\section{Quality assessment and data abstraction}

The Joanna Briggs Institute Meta-Analysis of Statistics Assessment and Review Instrument (JBI-MAStARI) was used for quality appraisal [25] (S1 Table). The quality of all the included studies was assessed by three authors (TT, GF, and FK). Any disagreement between the three authors was resolved by involving the other two authors (GF and ET) to independently assess the methodological quality to reach a consensus. Data were extracted using a standardized data extraction checklist on Microsoft Excel. Initially, duplicated literature was excluded by using Endnotes reference management. Then, studies were excluded by their titles. Next, studies that were found to be irrelevant to our study were screened by their abstracts. Full-text articles or reports were assessed for the remaining literature. Based on the preset inclusion and exclusion criteria, eligibility of the studies was evaluated. For the outcome variable (association between pregnancy intention and late initiation of ANC), data were extracted in a format of two by two tables, and then the log OR was calculated based on the findings of the original studies. The checklist for data extraction contains the title, author name, year of publication, region (the area where the study was conducted), study design, sample size, response rate, and the number of participants with the outcome (Table 1). When articles did not have adequate data, the corresponding authors of the research articles were contacted through their email.

\section{Heterogeneity and publication bias}

Cochrane $Q$ test (chi-squared statistic) and $I^{2}$ test statistic on forest plot were used to check heterogeneity among the included studies. Cochrane's $Q$ statistical heterogeneity test is considered as statistically significant at $p \leq 0.05 . I^{2}$ values of $0,25,50$, and $75 \%$ were considered as no, low, moderate, and high degrees of heterogeneity, respectively [32]. Subgroup analysis was conducted based on the definition of ANC given by different studies. Funnel plot asymmetry was used to check publication bias. In addition, Egger's weighted regression test 
Table 1 Summary of included studies regarding the association between the intention of pregnancy and delayed initiation of ANC among pregnant women in Ethiopia, 2019

\begin{tabular}{|c|c|c|c|c|c|c|c|c|c|c|c|c|}
\hline S.N & Author & Year & Region & $\begin{array}{l}\text { Study } \\
\text { design }\end{array}$ & Study area & $\begin{array}{l}\text { Definition of late } \\
\text { initiation of ANC }\end{array}$ & $\begin{array}{l}\text { Sample } \\
\text { size }\end{array}$ & $\begin{array}{l}\text { Planned } \\
\text { pregnancy }\end{array}$ & TOT & $\begin{array}{l}\text { Unplanned } \\
\text { pregnancy }\end{array}$ & TOT & $\begin{array}{l}\text { OR }(95 \% \\
\text { Cl) }\end{array}$ \\
\hline 1 & $\begin{array}{l}\text { Mengesha } \\
\text { et al. .[34] }\end{array}$ & 2017 & SNNP & $\begin{array}{l}\text { Cross- } \\
\text { sectional }\end{array}$ & Sidama zone & $\begin{array}{l}\text { ANC initiation after } 12 \\
\text { weeks of gestation }\end{array}$ & 631 & 377 & 479 & 99 & 129 & $\begin{array}{l}0.89 \\
(0.56 \\
1.41)\end{array}$ \\
\hline 2 & $\begin{array}{l}\text { Desta et al. } \\
\text { [35] }\end{array}$ & 2018 & SNNP & $\begin{array}{l}\text { Cross- } \\
\text { sectional }\end{array}$ & Hadiya zone & $\begin{array}{l}\text { ANC initiation after } 12 \\
\text { weeks of gestation }\end{array}$ & 770 & 329 & 404 & 138 & 143 & $\begin{array}{l}6.29 \\
(2.49 \\
15.89)\end{array}$ \\
\hline 3 & $\begin{array}{l}\text { Feleke, } \\
\text { Yohannes } \\
\text { et al. [36] }\end{array}$ & 2015 & SNNP & $\begin{array}{l}\text { Cross- } \\
\text { sectional }\end{array}$ & $\begin{array}{l}\text { Arbaminch } \\
\text { town }\end{array}$ & $\begin{array}{l}\text { starting ANC after } 16 \\
\text { weeks of gestation }\end{array}$ & 409 & 208 & 269 & 130 & 140 & $\begin{array}{l}3.81 \\
(1.88, \\
7.70)\end{array}$ \\
\hline 4 & $\begin{array}{l}\text { Amtatachew } \\
\text { et al. [37] }\end{array}$ & 2013 & Amhara & $\begin{array}{l}\text { Cross- } \\
\text { sectional }\end{array}$ & $\begin{array}{l}\text { Debre berhan } \\
\text { town }\end{array}$ & $\begin{array}{l}\text { first ANC initiation after } \\
12 \text { weeks of gestation }\end{array}$ & 465 & 167 & 241 & 162 & 205 & $\begin{array}{l}1.66 \\
(1.08, \\
2.57)\end{array}$ \\
\hline 5 & $\begin{array}{l}\text { Tadele Girum } \\
\text { [38] }\end{array}$ & 2016 & SNNP & $\begin{array}{l}\text { Cross- }^{-} \\
\text {sectional }\end{array}$ & Dilla town & $\begin{array}{l}\text { First ANC initiation after } \\
16 \text { weeks of gestation }\end{array}$ & 362 & 118 & 271 & 64 & 91 & $\begin{array}{l}3.07 \\
(1.84, \\
5.11)\end{array}$ \\
\hline 6 & $\begin{array}{l}\text { Belayneh et al. } \\
\text { [39] }\end{array}$ & 2014 & Amhara & $\begin{array}{l}\text { Cross- } \\
\text { sectional }\end{array}$ & Gondar town & $\begin{array}{l}\text { First ANC initiation after } \\
12 \text { weeks of gestation }\end{array}$ & 369 & 178 & 332 & 17 & 37 & $\begin{array}{l}0.74 \\
(0.37 \\
1.45)\end{array}$ \\
\hline 7 & $\begin{array}{l}\text { Wondwossen } \\
\text { et al. [40] }\end{array}$ & 2015 & Tigrai & $\begin{array}{l}\text { Cross- }^{-} \\
\text {sectional }\end{array}$ & Adigrat town & $\begin{array}{l}\text { First ANC initiation after } \\
16 \text { weeks of gestation }\end{array}$ & 423 & 195 & 393 & 20 & 23 & $\begin{array}{l}6.76 \\
(1.98 \\
23.14)\end{array}$ \\
\hline 8 & $\begin{array}{l}\text { Hussen et al. } \\
{[43]}\end{array}$ & 2016 & SNNP & $\begin{array}{l}\text { Cross- } \\
\text { sectional }\end{array}$ & $\begin{array}{l}\text { Wollaita } \\
\text { Soddo zone }\end{array}$ & $\begin{array}{l}\text { First ANC initiation after } \\
16 \text { weeks of gestation }\end{array}$ & 256 & 131 & 197 & 39 & 58 & $\begin{array}{l}1.03 \\
(0.55 \\
1.92)\end{array}$ \\
\hline 9 & $\begin{array}{l}\text { Kahasse et al. } \\
{[45]}\end{array}$ & 2017 & $\mathrm{AA}$ & $\begin{array}{l}\text { Case- } \\
\text { control }\end{array}$ & AA & $\begin{array}{l}\text { First ANC initiation after } \\
12 \text { weeks of gestation }\end{array}$ & 402 & 102 & 348 & 32 & 54 & $\begin{array}{l}3.50 \\
(1.94 \\
6.32)\end{array}$ \\
\hline 10 & Yilala [29] & 2015 & AA & $\begin{array}{l}\text { Cross- } \\
\text { sectional }\end{array}$ & AA & $\begin{array}{l}\text { First ANC initiation after } \\
12 \text { weeks of gestation }\end{array}$ & 426 & 90 & 314 & 50 & 93 & $\begin{array}{l}2.89 \\
(1.79 \\
4.65)\end{array}$ \\
\hline 11 & $\begin{array}{l}\text { Haileab } \\
\text { Fekadu et al. } \\
{[12]}\end{array}$ & 2019 & Amhara & $\begin{array}{l}\text { Cross- } \\
\text { sectional }\end{array}$ & $\begin{array}{l}\text { South } \\
\text { Gondar zone }\end{array}$ & $\begin{array}{l}\text { First ANC initiation after } \\
12 \text { weeks of gestation }\end{array}$ & 364 & 127 & 270 & 64 & 94 & $\begin{array}{l}2.40 \\
(1.46, \\
3.94)\end{array}$ \\
\hline 12 & $\begin{array}{l}\text { Tesfalidet et al. } \\
\text { [42] }\end{array}$ & 2014 & SNNP & $\begin{array}{l}\text { Cross- } \\
\text { sectional }\end{array}$ & $\begin{array}{l}\text { Kembata } \\
\text { Tembaro } \\
\text { zone }\end{array}$ & $\begin{array}{l}\text { First ANC initiation after } \\
16 \text { weeks of gestation }\end{array}$ & 401 & 199 & 300 & 70 & 82 & $\begin{array}{l}2.96 \\
(1.53 \\
5.71)\end{array}$ \\
\hline 13 & $\begin{array}{l}\text { Hanna G. et al. } \\
\text { [41] }\end{array}$ & 2017 & AA & $\begin{array}{l}\text { Cross- } \\
\text { sectional }\end{array}$ & AA & $\begin{array}{l}\text { First ANC initiation after } \\
16 \text { weeks of gestation }\end{array}$ & 997 & 265 & 699 & 145 & 276 & $\begin{array}{l}1.81 \\
(1.36 \\
2.40)\end{array}$ \\
\hline 14 & $\begin{array}{l}\text { Atsede et al. } \\
\text { [44] }\end{array}$ & 2018 & Amhara & $\begin{array}{l}\text { Cross- } \\
\text { sectional }\end{array}$ & $\begin{array}{l}\text { Debremarkos } \\
\text { town }\end{array}$ & $\begin{array}{l}\text { First ANC initiation after } \\
16 \text { weeks of gestation }\end{array}$ & 320 & 67 & 152 & 40 & 68 & $\begin{array}{l}1.81 \\
(1.01 \\
3.23)\end{array}$ \\
\hline
\end{tabular}

was used to check publication bias [33]. A $p$ value of less than 0.05 was used to declare the statistical significance of publication bias.

\section{Data analysis}

The necessary information was extracted from each original study by using a format prepared in a Microsoft Excel spreadsheet. Then the data were exported to STATA for Windows version 14 and used to calculate the pooled effect size with $95 \%$ confidence intervals of pregnancy intention on late initiation of ANC using the DerSimonian and Laird random effects meta-analysis (random effects model). The logarithm and standard error of the odds ratio (OR) for each included study were generated using "generate" command in STATA. Meta-regression was conducted to identify the source of heterogeneity, and statistically significant results were declared in the presence of heterogeneity.

\section{Result}

Study selection

A systematic search of electronic databases and library catalogs identified a total of 677 published articles and three unpublished studies. Of the total published and 
unpublished identified studies, 97 duplicates papers were removed and 553 records were removed by reviewing titles and abstracts. The abstracts and full text of the remaining 30 studies were assessed and screened for eligibility criteria based on the outcome variable (late initiation of ANC) and 16 studies were excluded because they failed to meet the eligibility criteria (poor quality based on the selection criteria, their regression tables did not include intention of pregnancy as an independent variable).

Finally, 14 articles which scored 7 and above on the JBI quality appraisal eligibility criteria were included in the systematic review and meta-analysis. We used the Preferred Reporting Items for Systematic Reviews and Meta-Analyses (PRISMA) flow diagram to present the systematic review overview (Fig. 1).

\section{Characteristics of included studies}

Of the total included studies, 13 studies were crosssectional $[12,29,34-44]$ and only one study was a casecontrol study design [45]. They had an overall of sample size 6390 pregnant women in Ethiopia, and the study sample sizes ranged from 256 to 997 participants. The studies were conducted from 2013 to 2019 in various regions of the country. Of the fourteen studies included in the final analysis, six studies were conducted in the SNNP region [34-36, 38, 42, 43], four were conducted in the Amhara region [12, 37, 39, 44], and three were conducted in Addis Ababa [29, 41, 45]. The remaining study was conducted in Tigrai region [40].

The findings of original studies showed varied and inconclusive association between the pregnancy intention and delayed initiation of ANC. The result was a significantly positive and negative association in some studies and insignificant in other studies. Of those studies that showed a significantly positive association, the strongest association was observed in the study conducted in the Tigrai region [40] with an odds ratio of 6.77 (CI 1.9823.15). The smallest odds ratio for the effect of pregnancy intention on late initiation of ANC (0.74) was reported in the study conducted in the Amhara region [39] (Table 1).

\section{Association between pregnancy intention and late initiation of ANC}

In this meta-analysis, we found significant heterogeneity across studies $\left(I^{2}=73.5 \%, p=0.00\right)$, which is an indicator to use random effects model to estimate the pooled effect of pregnancy intention on the delayed initiation of ANC reported by the fourteen studies with inverse variance.

This meta-analysis found that pregnancy intention had statistically significant effects on delayed initiation of ANC. The finding showed that there is an increased odds of delayed antenatal care among women

680 studies $(676$ published studies from different databases and 4 unpublished studies from Addis Ababa digital library and other sources

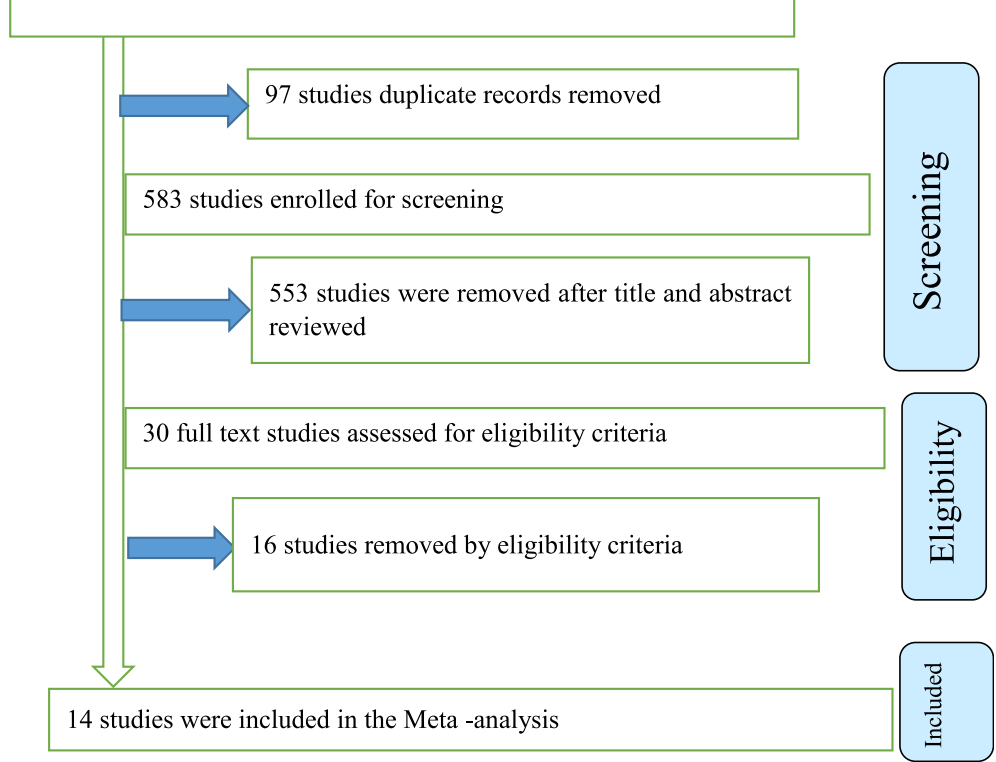

Fig. 1 PRISMA flow diagram of included studies in the systematic review and meta-analysis of the association between intention of pregnancy and late initiation of ANC among pregnant women in Ethiopia, 2019 


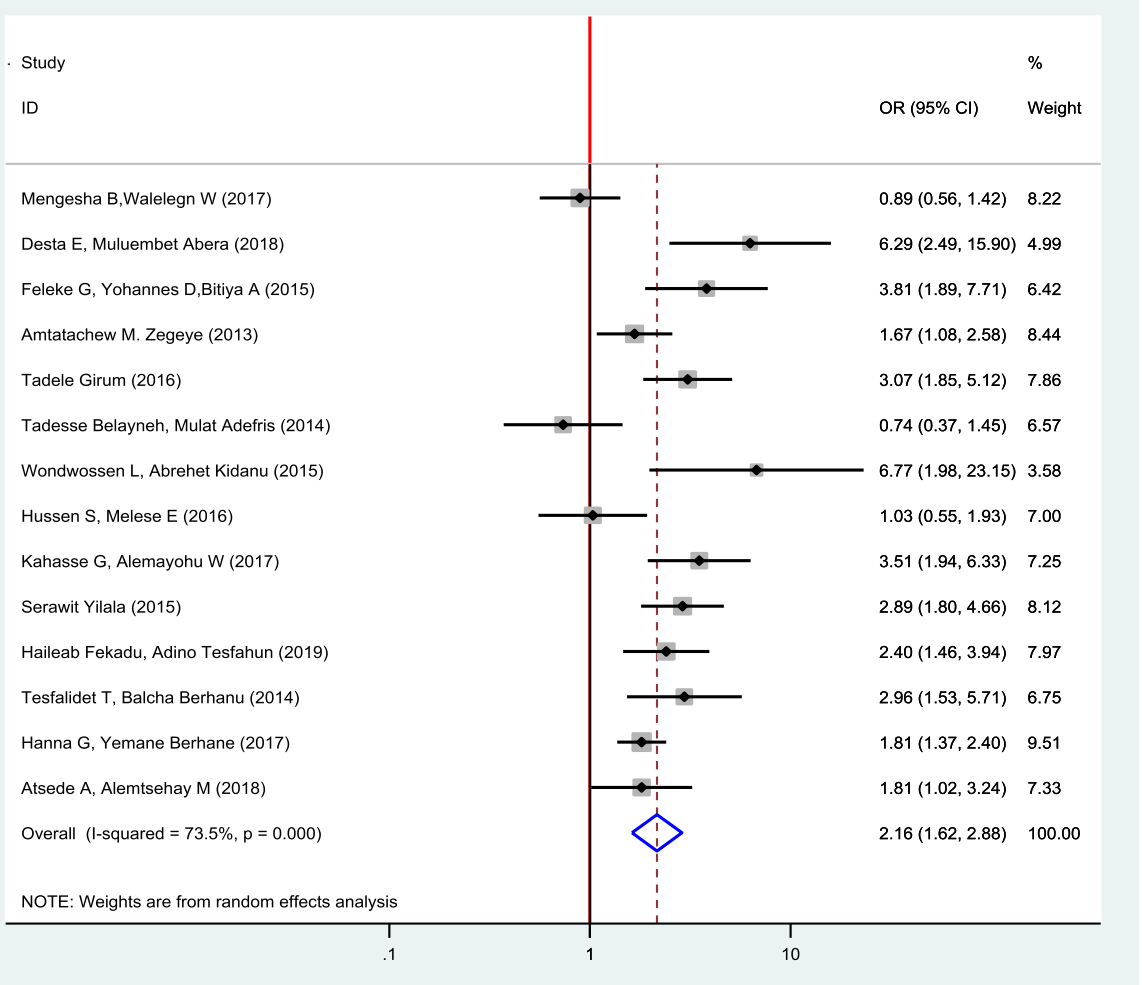

Fig. 2 Forest plot of the pooled estimate of the association between pregnancy intention and delayed initiation of ANC among pregnant women in Ethiopia, 2019

with unintended pregnancies as compared to women with intended pregnancies (OR 2.16, 95\% CI 1.62, 2.88) (Fig. 2).

To identify the possible sources of heterogeneity, different factors associated with the heterogeneity such as sample size and year of publication were computed using meta-regression models, but all of these variables were not found to be statistically significant. The presence of publication bias was assessed using a funnel plot and Egger's test at a 5\% level of significance (Fig. 3). Although visual examination of the funnel plot shows it to be asymmetric, Egger's test was insignificant for the presence of publication bias $(p=0.28)$ (Table 2).

Sensitivity analysis of the studies was done to test the effect of a single study on the pooled result of the remaining studies using random effect model. We found

Table 2 Related factors with heterogeneity of association between pregnancy intention and delayed initiation of ANC among pregnant women in Ethiopia, 2019

\begin{tabular}{lll}
\hline Variables & Coefficients & $\boldsymbol{p}$ value \\
\hline Publication year & 0.0404114 & 0.719 \\
Sample size & 0.0000683 & 0.943 \\
\hline
\end{tabular}

no strong evidence for influence of individual study on remaining studies (Fig. 4).

Subgroup analysis was conducted based on the definition of late initiation of ANC given by different studies. Accordingly, the odds of delayed ANC initiation among women with unintended pregnancy was 2.10 times higher as compared to women with intended pregnancy with studies used 12 weeks definition of delayed initiation of ANC (OR 2.10, 95\% CI 1.23, 3.24). The odds of delayed ANC initiation women with unintended pregnancy was 2.33 times higher as compared to women with intended pregnancy with studies used 16 weeks definition of delayed initiation of ANC (OR 2.33, 95\% CI 1.63, 3.32) (Fig. 5).

\section{Discussion}

Timely initiation and continuously attending ANC service can improve maternal and child health outcomes. This is very important in a low-income country such as Ethiopia where the health condition of the mother is very poor. The current systematic review and metaanalysis estimated the pooled effect of pregnancy intention on delayed initiation of ANC among pregnant women in Ethiopia. 


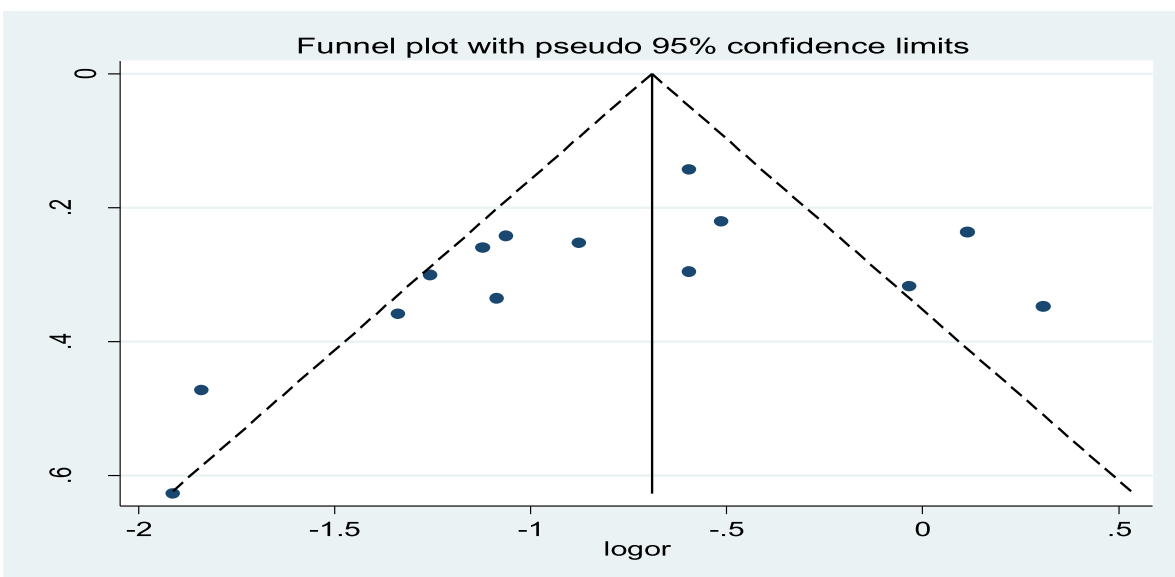

Fig. 3 Funnel plot with 95\% confidence limit of the association between pregnancy intention and delayed initiation of ANC among pregnant women in Ethiopia, 2019

The result of this study found that pregnancy intention had statistically a significant effect on late initiation of ANC among pregnant women. The overall pooled estimate of this analysis indicated the odds of delayed initiation of ANC among women who experienced unintended pregnancy were higher than their counterparts. Delaying time of ANC initiation endangers both maternal and fetal health. This is due to the fact that a delay in ANC commencement decreases the full benefit of women from effective ANC follow-up and timely initiation of ANC [46]. It is believed that intended pregnancies are more cared for by pregnant women and their spouses; this enables women to book for ANC timely.

The finding is consistent with a previous systematic review and meta-analysis conducted in Ethiopia on overall factors associated with late initiation of ANC, in which women with intended pregnancy were less likely to delay their ANC initiation [13]. The possible reason for delayed initiation of ANC among women with unintended pregnancy may be the absence of good health care behavior due to lack of family or social support. Furthermore, the finding of this meta-analysis is similar to studies conducted in Tanzania in which unintended pregnancy decreased early initiation of ANC due to late recognition of pregnancy and socioeconomic factors [22, 46].

A study conducted in Kenya showed that women who reported unintended pregnancy were either less likely to receive antenatal care or more likely to delay ANC initiation [47], which is consistent with our finding. Another study from South Africa also reported that unintended

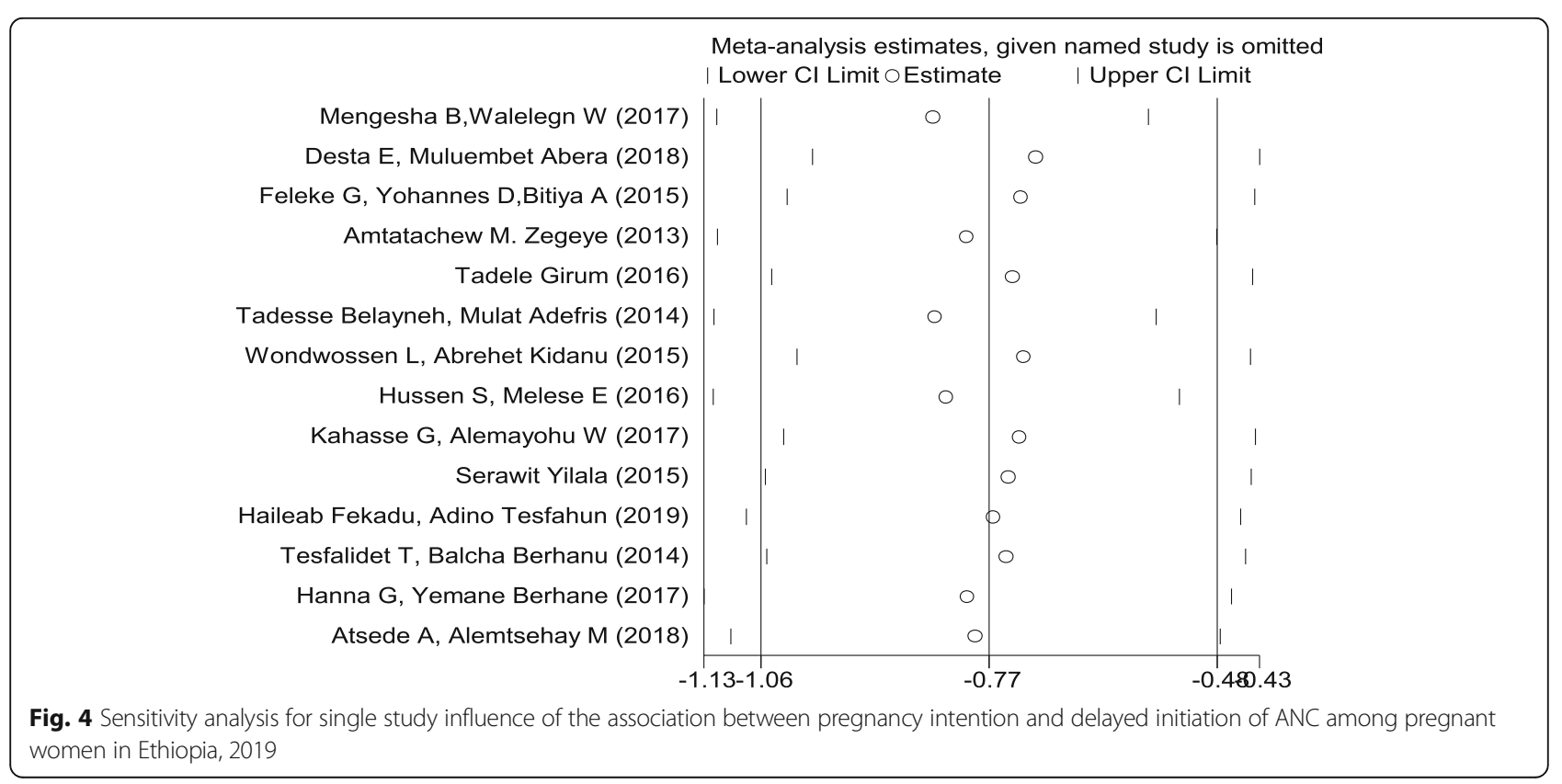




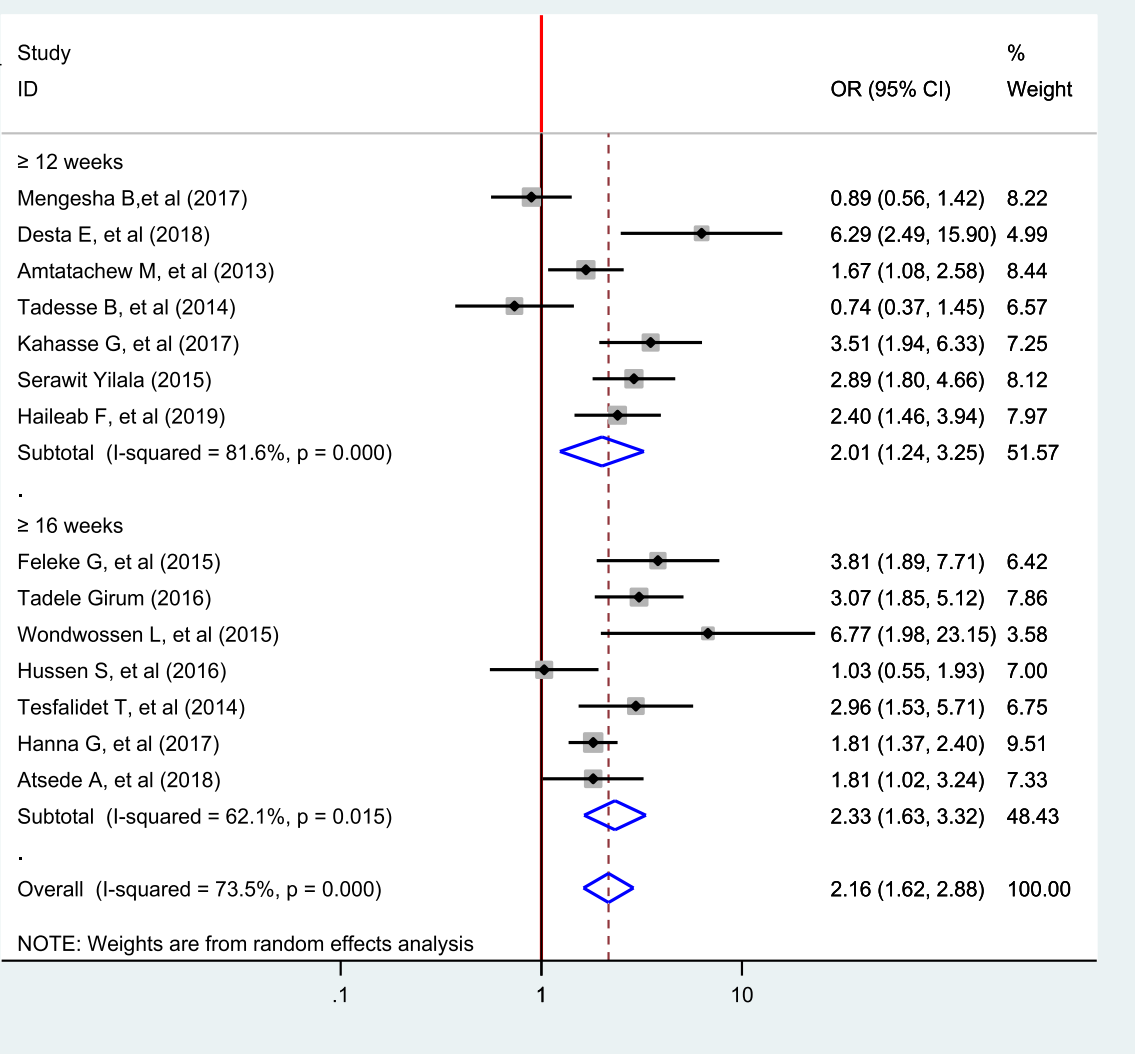

Fig. 5 Subgroup analysis of the association between pregnancy intention and delayed initiation of ANC in Ethiopia, 2019

pregnancy, which was attributed mainly to failure of family planning, was a significant predictor of late initiation of ANC [48-50]. This might be if pregnancy is unintended pregnancy, the intention to care for pregnancy is low and the effort to hide a pregnancy is very high because of social fear and custom of the community. Similarly, the finding of the current study is consistent with a national-level study from Rwanda, which stated women with unintended pregnancy are less likely to attend pregnancy and more likely in late initiation of ANC [51]. The result from Zambia and Myanmar reveals the same finding in which women who fell pregnant unintentionally had a higher odds of starting ANC late, which is consistent with our current result $[52,53]$.

Women with unintended pregnancy may delay ANC initiation due to lack of knowledge, lack of decision making power, lack of money, or cultural factors [46]. Unintended pregnancies are also related to social and cultural determinants of health-seeking behaviors such as ineffective use of family planning, sexual violence, and barriers to access to health care; these all may be associated with late initiation of ANC [22].

The strength of this study is that various databases were used to search literature, and both published and unpublished studies were included in the study. This study has some limitations. First, most of the included studies in the final analysis were cross-sectional study design which may decrease causal conclusion between pregnancy intention and delayed initiation of ANC.

\section{Conclusion}

This systematic review and meta-analysis demonstrated that women's pregnancy intention was associated with late commencement of antenatal care in Ethiopia. To reduce unintended pregnancy, the reproductive health services that focus on strengthening the women utilization of family planning are demanded. Increased effort should be made to improve women's behavior towards contraceptive use through health education and counseling, especially those with unintended pregnancies. Furthermore, health education, counseling, and communication campaigns related to the timing of ANC and frequency should be promoted nationally.

\section{Supplementary information}

Supplementary information accompanies this paper at https://doi.org/10. 1186/s13643-020-01449-9.

Additional file 1: Table S1. JBI Quality Assessment tool.

Additional file 2: Table S2. Result of database search. 


\section{Abbreviations}

ANC: Antenatal care; Cl: Confidence interval; SSA: Sub-Saharan Africa; SDG: Sustainable Development Goals; OR: Odds ratio; SNNP: Southern Nation Nationalities and People; WHO: World Health Organization

\section{Acknowledgements}

We would like to thank all authors of the studies included in this systematic review and meta-analysis.

\section{Authors' contributions}

$\Pi$ involved in proposal development and statistical analysis. GF, ET, GF, and FK involved in the design, selection of articles, and data extraction. GF, ET, GF, and FK involved in developing the initial drafts of the manuscript. All authors participated in the final preparation of the manuscript and they approved the final draft of the manuscript for submission.

\section{Funding}

No funding was obtained for this study

\section{Availability of data and materials}

All data analyzed during this study are included in the manuscript.

\section{Ethics approval and consent to participate}

Not applicable

\section{Consent for publication}

Not applicable

\section{Competing interests}

The authors declare that they have no competing interests.

\section{Author details}

${ }^{1}$ Department of Public Health, Institutes of Health Sciences, Wollega University, Nekemte, Ethiopia. ${ }^{2}$ Department of Nursing, Institutes of Health Sciences, Wollega University, Nekemte, Ethiopia. ${ }^{3}$ Department of Pharmacy, Institutes of Health Sciences, Wollega University, Nekemte, Ethiopia. ${ }^{4}$ Department of Public Health, College of Health Sciences, Jimma University, Jimma, Ethiopia.

Received: 20 April 2020 Accepted: 7 August 2020

Published online: 20 August 2020

\section{References}

1. Kerber KJ, de Graft-Johnson JE, Bhutta ZA, Okong P, Starrs A, Lawn JE. Continuum of care for maternal, newborn, and child health: from slogan to service delivery. The Lancet. 2007;370(9595):1358-69.

2. UNICEF, ANTENATAL CARE 2019

3. UNICEF, Global delivery care coverage and trends. 2019.

4. Langlois ÉV, Miszkurka M, Zunzunegui MV, Ghaffar A, Ziegler D, Karp I. Inequities in postnatal care in low-and middle-income countries: a systematic review and meta-analysis. Bulletin of the World Health Organization. 2015:93:259-70G

5. Nations U. The Sustainable Development Goals Report 2019. New York; 2019.

6. Chou D, Daelmans B, Jolivet RR, Kinney M, Say L. Ending preventable maternal and newborn mortality and stillbirths. Bmj. 2015;351:h4255.

7. Organization. W.H. WHO recommendations on antenatal care for a positive pregnancy experience: World Health Organization; 2016.

8. Moller AB, Petzold M, Chou D, Say L. Early antenatal care visit: a systematic analysis of regional and global levels and trends of coverage from 1990 to 2013. The Lancet Global Health. 2017;5(10):e977-83.

9. Yan J. The effects of prenatal care utilization on maternal health and health behaviors. Health economics. 2017 Aug;26(8):1001-18.

10. Tekelab T, Chojenta C, Smith R, Loxton D. The impact of antenatal care on neonatal mortality in sub-Saharan Africa: a systematic review and metaanalysis. PloS one. 2019;14(9)

11. Ejeta E, Dabsu R, Zewdie O, Merdassa E. Factors determining late antenatal care booking and the content of care among pregnant mother attending antenatal care services in East Wollega administrative zone. West Ethiopia. Pan African Medical Journal. 2017;27(1).
12. Wolde HF, Tsegaye AT, Sisay MM. Late initiation of antenatal care and associated factors among pregnant women in Addis Zemen primary hospital, South Gondar. Ethiopia. Reproductive health. 2019;16(1):73.

13. Tesfaye G, Loxton D, Chojenta C, Semahegn A, Smith R. Delayed initiation of antenatal care and associated factors in Ethiopia: a systematic review and meta-analysis. Reproductive health. 2017;14(1):150.

14. Tekelab T, Chojenta C, Smith R, Loxton D. Factors affecting utilization of antenatal care in Ethiopia: A systematic review and meta-analysis. PloS one. 2019;14(4).

15. Dibaba $Y$, Fantahun M, Hindin MJ. The effects of pregnancy intention on the use of antenatal care services: systematic review and meta-analysis. Reproductive health. 2013;10(1):50.

16. Kuroki LM, Allsworth JE, Redding CA, Blume JD. Peipert JF. Is a previous unplanned pregnancy a risk factor for a subsequent unplanned pregnancy? Am J Obstet Gynecol. 2008;199(5):517-e1.

17. Mohllajee AP, Curtis KM, Morrow B, Marchbanks PA. Pregnancy intention and its relationship to birth and maternal outcomes. Obstetrics and Gynecology. 2007;109(3):678-86.

18. Bearak J, Popinchalk A, Alkema L, Sedgh G. Global, regional, and subregional trends in unintended pregnancy and its outcomes from 1990 to 2014: estimates from a Bayesian hierarchical model. The Lancet Global Health. 2018;6(4):e380-9.

19. Cheng D, Schwarz EB, Douglas E, Horon I. Unintended pregnancy and associated maternal preconception, prenatal and postpartum behaviors. Contraception. 2009;79(3):194-8.

20. Hardee K, Eggleston E, Wong EL, Hull TH. Unintended pregnancy and women's psychological well-being in Indonesia. J Biosoc Sci. 2004;36(5):617-26.

21. Abajobir AA, Maravilla JC, Alati R, Najman JM. A systematic review and meta-analysis of the association between unintended pregnancy and perinatal depression. Journal of affective disorders. 2016;192:56-63.

22. Exavery A, Kanté AM, Hingora A, Mbaruku G, Pemba S, Phillips JF. How mistimed and unwanted pregnancies affect timing of antenatal care initiation in three districts in Tanzania. BMC pregnancy and childbirth. 2013; 13(1):35.

23. Eggleston E. Unintended pregnancy and women's use of prenatal care in Ecuador. Social science and medicine. 2000;51(7):1011-8.

24. Moher D, Liberati A, Tetzlaff J, Altman DG, Prisma Group. Reprint-preferred reporting items for systematic reviews and meta-analyses: the PRISMA statement. Physical therapy. 2009;89(9):873-880.

25. Institute JB, Meta-analysis of statistics: assessment and review instrument (JBI Mastari). Adelaide: Joanna Briggs Institute 2006. 20032007.

26. Megersa G. Factors associated with timely first antenatal care booking among pregnant women attending antenatal clinics in Asella town public health institutions, Arsi zone Oromia regional state, Ethiopia, 2017 (Doctoral dissertation, Addis Ababa University).

27. Ngongo N. Health system predictors of antenatal care compliance among rural congolese women.

28. Ragolane VJ. Factors contributing to late antenatal care booking in Mopani District of Limpopo Province (Doctoral dissertation).

29. Yilala S. Assesment of late initiation of antenatal care and associated factors among antenatal care attendees in selected health centers of Addis Ababa. Ethiopia: Doctoral dissertation, Addis Ababa University); 2015.

30. Brown SS, Eisenberg L, editors. The best intentions: unintended pregnancy and the well-being of children and families: National Academies Press; 1995.

31. B Brown SS, Eisenberg L. Unintended pregnancy and the well-being of children and families. JAMA. 1995;274(17):1332.

32. Higgins JP, Thompson SG. Quantifying heterogeneity in a meta-analysis. Statistics in medicine. 2002;21(11):1539-58.

33. Begg CB, Mazumdar M. Operating characteristics of a rank correlation test for publication bias. Biometrics. 1994:1088-101.

34. Geta MB, Yallew WW. Early initiation of antenatal care and factors associated with early antenatal care initiation at health facilities in southern Ethiopia. Advances in Public Health. 2017;2017

35. Abame DE, Abera M, Tesfay A, Yohannes Y, Ermias D, Markos T, Goba G. Relationship between unintended pregnancy and antenatal care use during pregnancy in Hadiya zone Southern Ethiopia. J Reprod Fertil. 20(1):42.

36. Gebremeskel F, Dibaba Y, Admassu B. Timing of first antenatal care attendance and associated factors among pregnant women in Arba Minch Town and Arba Minch District, Gamo Gofa Zone, South Ethiopia. Int J Environ Res Public Health. 2015;2015. 
37. Zegeye AM, Bitew BD, Koye DN. Prevalence and determinants of early antenatal care visit among pregnant women attending antenatal care in Debre Berhan Health Institutions Central Ethiopia. Afr J Reprod Health. 2013;17(4).

38. Kondale $\mathrm{M}$, Tumebo $\mathrm{T}$, Gultie $\mathrm{T}$, Megersa $\mathrm{T}$, Yirga $\mathrm{H}$. Timing of first antenatal care visit and associated factors among pregnant women attending anatal clinics in Halaba Kulito governmental health institutions, 2015. J Women's Health Care. 2016;5(308):2167-0420.

39. Belayneh T, Adefris M, Andargie G. Previous early antenatal service utilization improves timely booking: cross-sectional study at university of Gondar hospital, northwest Ethiopia. Journal of pregnancy. 2014;2014.

40. Lerebo W, Kidanu A, Tsadik M. Magnitude and associated factors of late booking for antenatal Care in Public Health Centers.

41. Gulema H, Berhane Y. Timing of first antenatal care visit and its associated factors among pregnant women attending public health facilities in Addis Ababa, Ethiopia. Ethiopian J Health Sci. 2017:27(2):139-46.

42. Tekelab T, Berhanu B. Factors associated with late initiation of antenatal care among pregnant women attending antenatal Clinic at Public Health Centers in Kembata Tembaro zone, southern Ethiopia. Science, Technology and Arts Research Journal. 2014;3(1):108-15.

43. Hussen SH, Melese ES, Dembelu MG. Timely initiation of first antenatal care visit of pregnant women attending antenatal care service. J Women's Health Care. 2016:5(346):2167-0420.

44. Ewunetie AA, Munea AM, Meselu BT, Simeneh MM, Meteku BT. DELAY on first antenatal care visit and its associated factors among pregnant women in public health facilities of Debre Markos town, North West Ethiopia. BMC pregnancy and childbirth. 2018;18(1):173.

45. Gebrekidan K, Worku A. Factors associated with late ANC initiation among pregnant women in select public health centers of Addis Ababa, Ethiopia: unmatched case-control study design. Pragmatic and observational research. 2017:8:223.

46. Gross K, Alba S, Glass TR, Schellenberg JA, Obrist B. Timing of antenatal care for adolescent and adult pregnant women in south-eastern Tanzania. BMC pregnancy and childbirth. 2012;12(1):16.

47. Ochako R, Gichuhi W. Pregnancy wantedness, frequency and timing of antenatal care visit among women of childbearing age in Kenya. Reproductive health. 2016;13(1):51.

48. Kaswa R, Rupesinghe GF, Longo-Mbenza B. Exploring the pregnant women's perspective of late booking of antenatal care services at Mbekweni Health Centre in Eastern Cape, South Africa. Afr J Primary health care and family medicine. 2018;10(1):1-9.

49. Joy Ebonwu1, A.M., Margot Uys, Milton L. Wainberg3, Andrew Medina- and Marino1, Determinants of late antenatal care presentation in rural and peri-urban communities in South Africa: a cross-sectional study. PLOS ONE, 2018. 13(3).

50. Aliyu AA, Dahiru T. Predictors of delayed Antenatal Care (ANC) visits in Nigeria: secondary analysis of 2013 Nigeria Demographic and Health Survey (NDHS). The Pan East Afr Med J. 2017;26.

51. Manzi A, Munyaneza F, Mujawase F, Banamwana L, Sayinzoga F, Thomson DR, Ntaganira J, Hedt-Gauthier BL. Assessing predictors of delayed antenatal care visits in Rwanda: a secondary analysis of Rwanda demographic and health survey 2010. BMC pregnancy and childbirth. 2014;14(1):290.

52. Manda-Taylor L, Sealy DA, Roberts J. Factors associated with delayed antenatal care attendance in Malawi: results from a qualitative study. Med J Zambia. 2017:44(1):17-25.

53. Thin Z. Aung1, W.M.O., Win Khaing3, Nay Lwin2, Hlaing T. Dar2, Late initiation of antenatal care and its determinants: a hospital based crosssectional study. International Journal of Community Medicine and Public Health, 2016. 3(4).

\section{Publisher's Note}

Springer Nature remains neutral with regard to jurisdictional claims in published maps and institutional affiliations.

Ready to submit your research? Choose BMC and benefit from:

- fast, convenient online submission

- thorough peer review by experienced researchers in your field

- rapid publication on acceptance

- support for research data, including large and complex data types

- gold Open Access which fosters wider collaboration and increased citations

- maximum visibility for your research: over $100 \mathrm{M}$ website views per year

At BMC, research is always in progress.

Learn more biomedcentral.com/submissions 